\title{
Partial Leaf Chemical Profiles of a Desert Watermelon Species (Citrullus colocynthis) and Heirloom Watermelon Cultivars (Citrullus lanatus var. lanatus)
}

\author{
Kelechi Ogbuji and Gloria S. McCutcheon ${ }^{1}$ \\ Department of Biology, Claflin University, 400 Magnolia Street, Orangeburg, \\ SC 29115
}

\author{
Alvin M. Simmons \\ USDA-ARS, U.S. Vegetable Laboratory, 2700 Savannah Highway, Charleston, \\ $S C 29414$
}

\author{
Maurice E. Snook \\ USDA-ARS, Toxicology and Mycotoxin Research Unit, Richard B. Russell \\ Research Center, 950 College Station Road, Athens, GA 30605
}

Howard F. Harrison and Amnon Levi

USDA-ARS, U.S. Vegetable Laboratory, 2700 Savannah Highway, Charleston, $S C 29414$

Additional index words. breeding, germplasm, pest resistance, vegetable, aphids, whiteflies

\begin{abstract}
Whiteflies [Bemisia tabaci (Gennadius)] and aphids [Aphis gossypii Glover and Myzus persicae (Sulzer)] are serious threats to watermelon by direct feeding and by transmitting viruses of important virus diseases. The desert watermelon Citrullus colocynthis (L.) has been shown to exhibit resistance to these insect pests and could be a useful source for breeding resistance into watermelon [Citrullus lanatus var. lanatus (Thunbs) Matsum \& Nakai]. Using high-performance liquid chromatography (HPLC), we found differences among the chemical profiles of two U.S. PIs of $C$. colocynthis, one PI of C. lanatus var. citroides, and two heirloom watermelon (C. lanatus var. lanatus) cultivars ('Charleston Gray' and 'Mickey Lee'). Flavonoid and caffeic acid derivatives were identified in the leaf extracts by a combination of ultraviolet (UV) and mass spectrometry (MS) spectral analyses. Four phenolic derivatives of caffeic and/or ferulic acid were found to be essentially unique to $C$. colocynthis. Total flavonoid content was found to be approximately four to 18 times higher in C. colocynthis accessions and seven to nine times higher in $C$. lanatus var. citroides as compared with watermelon cultivars. Caffeoylglucose was also identified in the leaves of watermelon cultivars for the first time. Leaf sugar concentrations (198 to $211 \mathrm{mg} \cdot \mathrm{dL}^{-1}$ ), read from a glucometer, were statistically the same among the various germplasm entries. These results will help in the development of pest-resistant watermelon.
\end{abstract}

Watermelon [C. lanatus var. lanatus (Thunbs) Matsum \& Nakai] is an important crop globally. The origin of Citrullus spp. is in central or southern Africa (Jarret et al., 1997; Mujaju et al., 2010). On that continent, a wide variation of watermelon populations exists in diverse geographical regions and the fruit is considered a vital source of water and food for the native people and animals. As

Received for publication 30 Sept. 2011. Accepted for publication 28 Feb. 2012.

This article reports the results of research only. Mention of a proprietary product does not constitute an endorsement or recommendation for its use by the USDA

${ }^{1}$ To whom reprint requests should be addressed; e-mail gmccutcheon@claflin.edu.
Africa, are C. ecirrhosus Cogn. and C. rehmii De Winter (Robinson and Decker-Walters, 1997). C. lanatus var. lanatus is considered the progenitor of cultivated watermelon. The C. lanatus also includes the citron watermelon, C. lanatus (Thunbs) Matsum \& Nakai var. citroides (L.H. Bailey), which thrives in the deserts of southern Africa. It is known as the "Citron Watermelon," "Cow Watermelon," or "Tzama" (Jarret et al., 1997; Mujaju et al., 2010) and is considered a valuable germplasm source because different accessions of this subspecies contain resistance to diseases or pests (Levi et al., 2001b; Thies and Levi., 2007). The Citrullus germplasm collection maintained by the USDA-ARS Plant Genetic Resources and Conservation Unit, Griffin, GA (http://www.ars-grin.gov) includes over 1800 U.S. PIs. These PIs have been useful sources of germplasm for identifying disease or pest resistance that through intensive breeding programs could be incorporated into elite watermelon cultivars.

Whiteflies [Bemisia tabaci (Gennadius)] and aphids [Aphis gossypii Glover and Myzus persicae (Sulzer)] are major pests that feed on and transmit viruses to watermelon plants (Simmons et al., 2010; Simmons and Levi, 2002). However, several C. colocynthis PIs possess resistance to the sweetpotato whitefly, B. tabaci (Simmons and Levi, 2002), the twospotted spider mite, Tetranychus urtichae Koch (Lopez et al., 2005), and aphids (Simmons, unpublished data). These sources of germplasm should be useful for incorporating pest resistance into watermelon cultivars.

Very little work has been reported on the flavonoids and phenolics of watermelon, especially in the leaves. Most previous investigations of flavonoid or phenolic content of watermelon have been limited to determination by colorimetric methods (Asyaz et al., 2010; Chopra et al., 1974; Ibrahim et al., 2010; Tlili et al., 2011; Venkataramaiah and Narayana, 1983). Others have used acid hydrolysis before analysis to measure individual aglycone flavonoids (Harsh and Nag, 1988; Lugasi and Hovari, 2002; Meena and Patni, 2008) or phenolic acids (Das et al., 1967; Venkataramaiah and Narayana, 1983). Delazar et al. (2006) determined a number of flavononeC-glycosides in Citrullus colocynths fruits. To our knowledge, only the report of Maatooq et al. (1997) reports specific and novel hydroxybenzyl-flavonoids in the leaves of watermelon (Citrullus colocynthis) and only that of Chopra et al. (1974) relates phenolic content to resistance and susceptibility to disease (Alternaria cucumerina). Furthermore, there is no sufficient information on the chemical profile and compounds that may lure or repel insect pests and affect their feeding habits and reproduction on plants of watermelon cultivars vs. C. colocynthis PIs.

The objective of this study was to determine if differences exist in the chemical profiles of leaves of $C$. colocynthis PIs that showed whitefly resistance (Simmons and Levi, 2002) vs. those of susceptible watermelon cultivars $(C$. lanatus var. lanatus) and in a representative PI of the citron watermelon (C. lanatus var. citroides). 

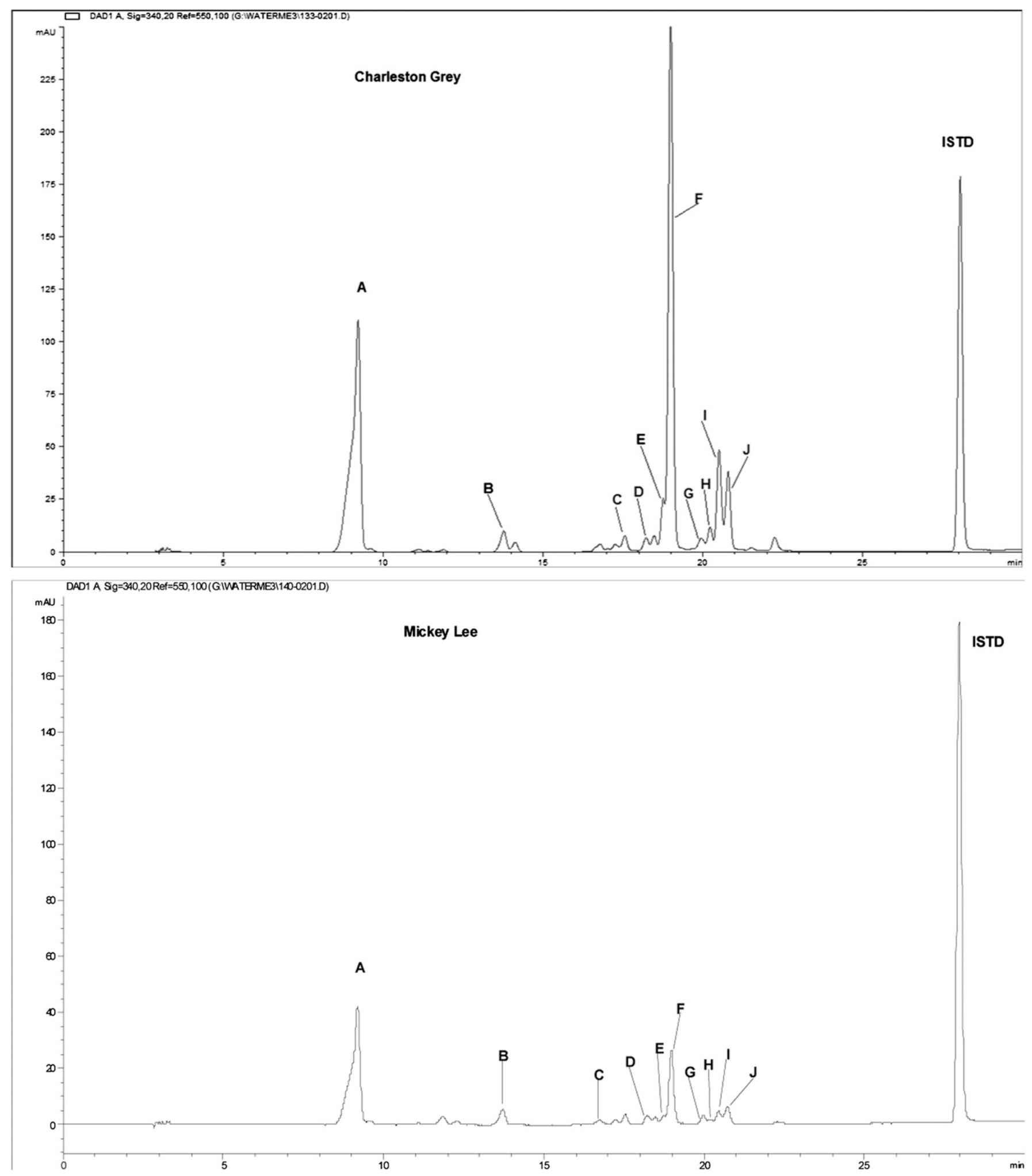

Fig. 1. High-performance liquid chromatography. Spectral patterns of flavonoids and caffeoyl-quinic acid (CQA) derivatives found in 'Charleston Gray' and 'Mickey Lee' watermelon, Citrullus lanatus var. lanatus. Refer to Table 1 for the meaning of the letters representing various peaks. ISTD = Chrysin.

\section{Materials and Methods}

Plant material. The plants in this study included the watermelon cultivars Charleston Gray and Mickey Lee (C. lanatus var. lanatus), the $C$. var. citroides PI 500354, and the C. colocynthis PI 386015 and PI 432337. The plants were grown in pots in the greenhouse using a standard watering regime.

Methanolic extract of fresh leaves of each Citrullus accession was made by clipping five healthy leaves from 7-week-old plants of each accession and cutting them into pieces with a pair of scissors. Three-gram portions of the leaf samples of each watermelon accession was then placed in separate $14 \times$ 7-cm, 118.5-mL glass bottles (a Teflon-lined cap was used) and $100 \mathrm{~mL}$ of methanol was added to each bottle. Chrysin (Sigma-Aldrich, Milwaukee, WI; recrystallized from amyl alcohol) was used as an internal standard. Three 

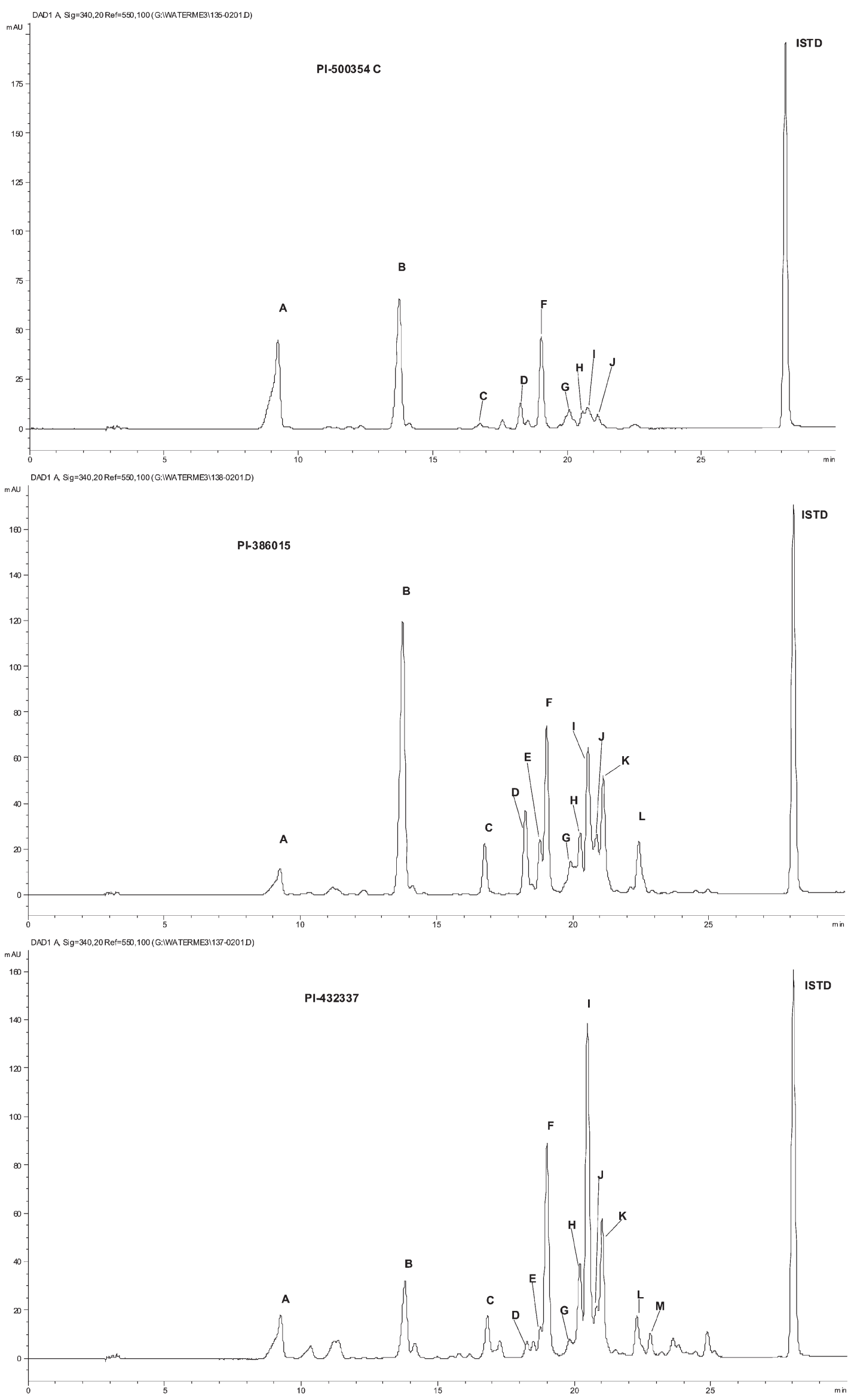

Fig. 2. High-performance liquid chromatography. Spectral patterns of flavonoids and caffeoyl-quinic acid (CQA) derivatives found in accessions PI 500354 (Citrullus citroides), PI 386015 (Citrullus lanatus var. colocynthis), and PI 432337 (Citrullus lanatus var. colocynthis). Letter C after PI 500354 represents the in-house designation assigned to this sample. Refer to Table 1 for the meaning of the letters representing peaks. ISTD $=$ Chrysin. 
milliliters of a methanolic solution $(4.8 \mathrm{mg}$ chrysin $/ 3 \mathrm{~mL}$ ) was added to each leaf extract and the solution mixed. The submerged leaves were subsequently further cut into smaller pieces with scissors and ground for $\approx 1$ min with a polytron (Kinematic-PCU-2; Brinkmann Instruments, Inc., Westbury, NY) equipped with a 6-mm diameter sawtooth grinder type of tissue cutter. The solutions were filtered through $0.45-\mu \mathrm{m}$ nylon- 66 filters in preparation for HPLC analysis.

High-performance liquid chromatography analysis. Extracts were analyzed once by reversed-phase HPLC using a $\mathrm{H}_{2} \mathrm{O} / \mathrm{MeOH}$ linear gradient from $10 \%$ to $100 \% \mathrm{MeOH}$ in $35 \mathrm{~min}$, a flow rate of $1 \mathrm{~mL} \cdot \mathrm{min}^{-1}$, and detection at $340 \mathrm{~nm}$. Each solvent contained $0.1 \% \mathrm{H}_{3} \mathrm{PO}_{4}$. Analyses were performed with a Beckman Ultrasphere C18, 5 micron (4.6 $\times$ $250 \mathrm{~mm}$; Beckman Instruments, Norcross, GA) column using a Hewlett-Packard 1050 diode array HPLC (Palo Alto, CA). Quantitation was performed by using chrysin's response factor. In addition to chrysin, other standards used were apigenin, caffeic acid, chlorogenic acid for tuning the HPLC-Mass Spectrophotometer (Sigma-Aldrich, St. Louis, MO), and isoorientin (Indofine Chemical Co., Belle Mead, NJ).

Identification. Preliminary identifications of compounds were by ultraviolet spectra and retention time correlations with standards. Also, mass spectra were obtained with a ThermoFinnigan LCQ HPLC/MS. For HPLC/MS, chlorogenic acid was used for tuning. Spectra were obtained in the negative ion mode. Gas chromatographic (GC) analyses were performed with a Hewlett-Packard $5890 \mathrm{GC}$ fitted with a DB-5 capillary column $(30 \mathrm{~m} \times$ $0.25 \mathrm{~mm}$ i.d., $1-\mathrm{mL} \cdot \mathrm{min}^{-1}$ flow rate); injector, $250{ }^{\circ} \mathrm{C}$; flame ionization detector, $350{ }^{\circ} \mathrm{C}$; linear temperature program, $100-320^{\circ} \mathrm{C}$ at $8{ }^{\circ} \mathrm{C} \cdot \mathrm{min}^{-1}$; splitless mode. Compounds were analyzed as their silylated derivatives.

Peaks $\mathrm{A}$ and $\mathrm{B}$ were isolated from the methanolic leaf extract of PI-500354 after

Table 1. High-performance liquid chromatography analysis showing the amount $\left(\mu \mathrm{g} \cdot \mathrm{g}^{-1}\right)$ of each chemical compound (lettered A to M) detected in the various Citrullus accessions.

\begin{tabular}{lrrrrrrrrrrrrr}
\hline & \multicolumn{10}{c}{ Chemical compounds $\left(\mu \mathrm{g} \cdot \mathrm{g}^{-1}\right)$} \\
\cline { 2 - 14 } & \multicolumn{1}{c}{$\mathrm{A}^{\mathrm{z}}$} & \multicolumn{1}{c}{$\mathrm{B}^{\mathrm{y}}$} & $\mathrm{C}^{\mathrm{x}}$ & \multicolumn{1}{c}{$\mathrm{D}^{\mathrm{w}}$} & $\mathrm{E}$ & \multicolumn{1}{c}{$\mathrm{F}$} & $\mathrm{G}$ & $\mathrm{H}$ & \multicolumn{1}{c}{$\mathrm{I}$} & $\mathrm{J}$ & $\mathrm{K}$ & $\mathrm{L}$ & $\mathrm{M}$ \\
\hline Charleston Gray & 2438 & 91 & 22 & 46 & - & 1582 & 44 & 59 & 240 & 266 & - & - & - \\
Mickey Lee & 759 & 66 & 17 & 36 & 33 & 281 & 31 & 16 & 47 & 56 & - & - & - \\
PI 500354 & 1044 & 803 & - & 102 & - & 424 & 123 & 90 & 68 & 26 & - & - & - \\
PI 386015 & 203 & 1458 & 247 & 416 & 213 & 748 & 274 & 275 & 747 & 268 & 576 & 279 & - \\
PI 432337 & 334 & 384 & 214 & 69 & 147 & 1053 & 88 & 414 & 1498 & 284 & 767 & 200 & 88 \\
\hline
\end{tabular}

${ }^{\mathrm{z}}$ Caffeoyl-glucose

"Isovitexin-2" -O-glucoside.

'Isoorientin.

wPeaks $\mathrm{D}$ to $\mathrm{M}=$ unknown phenolic derivatives of caffeic and/or ferulic acid.

$-=$ Undetected.

Table 2. Total flavonoid content ( $\mu \mathrm{g} \cdot \mathrm{g}^{-1}$ fresh leaf weight) of various Citrullus accessions. ${ }^{2}$

\begin{tabular}{lcc}
\hline Entry & No. & $\begin{array}{c}\text { Total flavonoid content } \\
\left(\mu \mathrm{g} \cdot \mathrm{g}^{-1}\right) \pm \mathrm{SEM}^{\mathrm{y}}\end{array}$ \\
\hline C. lanatus var. lanatus (Charleston Gray) & 2 & $171.7 \pm 7.8$ \\
C. lanatus var. lanatus (Mickey Lee) & 1 & 102.7 \\
C. lanatus var. citroides (PI 500354) & 3 & $905.7 \pm 109.5$ \\
C. colocynthis (PI 386015) & 1 & 1872.0 \\
C. colocynthis (PI 432337) & 1 & 452.9 \\
\hline
\end{tabular}

${ }^{\mathrm{z}}$ Data obtained by high-performance liquid chromatography.

${ }^{y_{S E M}}$ available for two entries.
'Mickey Lee') but are significantly higher in the C. lanatus var. citroides (PI 500354) or the C. colocynthis accessions (PI 386015 and PI 432337). Peaks $\mathrm{G}$ and $\mathrm{H}$ showed similar results. Peaks $\mathrm{C}, \mathrm{E}, \mathrm{K}$, and $\mathrm{L}$ are unique to the $C$. colocynthis PI 386015 and PI 432337 (Fig. 2). A clear peak $M$ was observed only in PI 432337, whereas peaks A, J, and F occurred in sufficient amounts in all accessions analyzed (Table 1; Figs. 1 and 2). The consistent elution of chrysin at $28 \mathrm{~min}$ for all analyzed samples suggests an overall high accuracy of the results.

A higher number of compounds was seen in chromatograms with $C$. colocynthis accessions as compared with those of $C$. lanatus var. lanatus or C. lanatus var. citroides accessions (Table 1; Figs. 1 and 2). Ultraviolet spectra and chromatography elution points are only indicators of what may be in a peak. It is possible that one or several of these compounds could be associated with the relative resistance of $C$. colocynthis to fluid-feeding pests. This could be possible for phenolic compounds of peaks K, L, or M. Although chlorogenic acid compounds are found in certain plants (Harrison et al., 2008), chlorogenic acid is unique to C. colocynthis accessions in Citrullus (Wu, 2007). The spectral analysis indicated that Peak A was caffeoyl-glucose: MS: $341(\mathrm{M}-\mathrm{H})$; MS²: 179 (M-caffeoyl), 161 (M-glucose). Acid hydrolysis yielded caffeic acid (confirmed by HPLC and GC retention time and MS) and glucose (confirmed by GC retention time). Peak B represented Isovitexin-2" -O-glucoside: MS: 593 (M-H); $\mathrm{MS}^{2}: 503$ (M-H-90), 473 (M-H120). Ultraviolet analysis indicated an apigenin or kaempferol aglycone. After isolation, this flavonoid (Peak B) appeared to lose a glucose moiety on acid hydrolysis and had a molecular mass of 594, suggesting that it might be either apigenin-diglucoside or kaempferolrhamnosyl-glucoside. After hydrolysis, isovitexin (MS:431; M-H) was identified by HPLC/ MS and liberated glucose by GC retention time. Mass fragmentation yielded ions of masses 503, 473, and 311. The abundance of the M$\mathrm{H}-90$ ion in the $\mathrm{MS}^{2}$ spectrum showed that the $\mathrm{C}$-bound sugar was attached to the C-6position, indicating an isovitexin structure. The data are in agreement with literature (Qimin et al., 1991) for 6-C-glucosyl-O-glycosylapigenin (glucosyl-isovitexin). Peak $\mathrm{C}$ represented Isoorientin: MS: 447 (M-H); MS $^{2}: 357$ (M-H-90), 327 (M-H-120). Ultraviolet spectra indicated a luteolin aglycone base.

Peaks D to $\mathrm{M}$ had broad ultraviolet maximum near $310 \mathrm{~nm}$, which indicated they were phenolic in nature, but HPLC/MS was inconclusive and requires further study.

Leaf sugar content was tested to investigate if sugar may play a direct role in the feeding preference on Citrullus accessions by pests such as whiteflies and aphids. Overall means for sugar concentrations were not significantly different among the genotypes $(P<0.05)$ (mean $=$ 198 to $\left.211 \mathrm{mg} \cdot \mathrm{dL}^{-1}\right)$. This suggests that leaf sugar content plays no role in insect preference of one Citrullus accession over another. Sugar specificity was not assayed. Hence, it is not known what types of sugars were involved. 
The C. colocynthis thrives in the deserts of northern Africa, the Middle East, and Asia, and a relatively wide genetic diversity exists among accessions of this species collected in these locations (Levi et al., 2001b). A wide genetic distance exists between $C$. colocynthis and watermelon cultivars (C. lanatus var. lanatus) (Jarret et al., 1997; Levi et al., 2001b). Still, the $C$. colocynthis should be a valuable germplasm source to improve resistance of watermelon cultivars to insect pests. A recent study (Hadizadeh et al., 2009) identified C. colocynthis as having antifungal activities. The HPLC analysis in this study identified several compounds unique to C. colocynthis (Table 1; Figs. 1 and 2). However, further analysis is needed to determine if these differences exist in a large number of accessions representing the Citrullus species or subspecies and to determine what role these compounds may have in pest resistance. We have constructed genetic populations derived from crosses between $C$. colocynthis and C. lanatus var. lanatus or $C$. lanatus var. citroides PIs that will be further evaluated for the presence or absence of the compounds identified in this study and determine if any of these compounds are associated with resistance to whiteflies, aphids, or other pests.

\section{Literature Cited}

Asyaz, S., I. Hussain, F. Khan, A. Muran, and I.U. Khan. 2010. Evaluation of chemical analysis profile of Citrullus coloynthis growing in southeastern area of Khyber Pukhtunkhwa Pakistan. World Appl. Sci. J. 10:402-405.

Chopra, B., J.S. Jhooty, and K.L. Bajaj. 1974. Biochemical differences between two varieties of watermelon resistant and susceptible to Alternaria cucunerina. Phytopathol. Zeitscrift 79:47-52.

Das, V.S.R., J.V.S. Rao, and K.N. Rao. 1967. Levels of phenolic acids during fruit growth in Citrullus colocynthis. Intl. J. Plant Physiol. $56: 466-468$.
Delazar, A., S. Gibbons, A.R. Kosari, H. Nazemiyeh, M. Modarresi, L. Nahar, and S.D. Sarker. 2006. Flavone-C-glycosides and cucurbitacin glycosides from Citrullus colocynthis. Daru, J. Faculty Pharmacy, Tehran Univ. Med. Sci. 14:109-114.

Hadizadeh, I., B. Peivastegan, and M. Kolahi. 2009. Antifungal activity of nettle, colocynth, oleander and konar extracts on plant pathogenic fungi. Pak. J. Biol. Sci. 12:58-63.

Harsh, M.L. and T.N. Nag. 1988. Flavonoids with antimicrobial activities of arid zone plants. Geobios (Jodhpur, India) 15:32-35.

Harrison, H.F., Jr., T.R. Mitchell, J.K. Peterson, W.P. Wechter, G.R. Majetich, and M.E. Snook. 2008. Contents of caffeoylquinic acid compounds in the storage roots of sixteen sweetpotato genotypes and their potential biological activity. J. Amer. Soc. Hort. Sci. 133:492-500.

Ibrahim, T.A., H.M. El-Hefnawy, and A.A. El-Hela 2010. Antioxidant potential and phenolic acid content of certain cucurbitaceous plants cultivated in Egypt. Nat. Prod. Res. 24:15371545 .

Jarret, R.L., L.C. Merrick, T. Holms, J. Evans, and M.K. Aradhya. 1997. Simple sequence repeats in watermelon [Citrullus lanatus (Thunb.) Matsum. \& Nakai]. Genome 40:433-441.

Levi, A., C.E. Thomas, A.P. Keinath, and T.C. Wehner. 2001a. Genetic diversity among watermelon (Citrullus lanatus and Citrullus colocynthis) accessions. Genet. Resources Crop Evol. 48:559-566.

Levi, A., C.E. Thomas, T.C. Wehner, and X. Zhang. 2001b. Low genetic diversity indicates the need to broaden the genetic base of cultivated watermelon. HortScience 36:10961101.

Lopez, R., A. Levi, B.M. Shepard, A.M. Simmons, and D.M. Jackson. 2005. Sources of resistance to two-spotted spider mite (Acari: Tetranychidae) in Citrullus spp. HortScience 40:16611663.

Lugasi, A. and J. Hovari. 2002. Flavonoid aglycons in foods of plant origin. II. Fresh and dried fruits. Acta Aliment. 31:63-71.

Maatooq, G.T., S.H. El-Sharkawy, M.S. Afifi, and J.P.N. Rosazza. 1997. C-p-hydroxybenzylglycoflavones from Citrullus colocynthis. Phytochem. 44:187-190.
Meena, M.C. and V. Patni. 2008. Isolation and identification of flavonoid 'quercetin' from Citrullus coloynthis (Linn.). Schrad. Asian J. Exp. Sci. 22:137-142.

Mujaju, C., J. Sehic, G. Werlemark, L. GarkavaGustavsson, M. Fatih, and H. Nybom. 2010. Genetic diversity in watermelon (Citrullus lanatus) landraces from Zimbabwe revealed by RAPD and SSR markers. Hereditas 147 : 142-153.

Qimin, L., H. Van Den Heuvel, O. Delorenzo, J. Corthout, L.A.C. Pieters, A.J. Vlietinck, and M. Claeys. 1991. Mass spectral characterizations of C-glycosidic flavonoids isolated from a medicinal plant (Passiflora incarnata). J. Chromatogr. B Biomed. Sci. Appl. 562: 435-446.

Robinson, R.W. and D.S. Decker-Walters. 1997. Cucurbits. CAB International Publishing, Oxon, UK.

SAS Institute. 2003. SAS/STAT user's guide. SAS Institute, Cary, NC.

Simmons, A.M., C.S. Kousik, and A. Levi. 2010 Combining reflective mulch and host plant resistance for sweetpotato whitefly (Hemiptera: Aleyrodidae) management in watermelon. Crop Prot. 29:898-902.

Simmons, A.M. and A. Levi. 2002. Sources of whitefly (Homoptera:Aleyrodidae) resistance in Citrullus for the improvement of cultivated watermelon. HortScience 37:581-584.

Thies, J.A. and A. Levi. 2007. Characterization of watermelon (Citrullus lanatus var. citroides) germplasm for resistance to root-knot nematodes. HortScience 42:1530-1533.

Tlili, I., C. Hdider, M.S. Lenucci, I. Riadh, H. Jebari, and G. Dalessandro. 2011. Bioactive compounds and antioxidant activities of different watermelon [Citullus lanatus (Thunb.) Mansfeld] cultivars as affected by fruit sampling area. J. Food Compost. Anal. 24:307314.

Venkataramaiah, C. and R.K. Narayana. 1983. Studies on indoyl-3-acetic acid oxidase and phenolic acid pattern in Cucurbitaceous fruits. Intl. J. Plant Physiol. 111:459-463.

Wu, L. 2007. Effect of chlorogenic acid on antioxidant activity of Flos Lonicerae extracts. J. Zhejiang Univ. Sci. B 8:673-679. 